\title{
PLANNING FOR THE SURVIVAL OF LINGUISTIC DIVERSITY
}

(Received 21 February 2005; accepted in revised form 26 June 2006)

\begin{abstract}
The prospect of the loss of linguistic diversity on a large scale has prompted scholars such as Fishman and others to propose programs of intervention to 'reverse language shift' (RLS). RLS theories and efforts are byproducts of European indigenous minority problems, and the ideological bias of Fishman's model of RLS privileges intergenerational transmission in the context of stable diglossia. This article examines the ideological underpinnings and utility of this framework as an appropriate model for stabilizing and revitalizing indigenous languages. I question the assumptions and theoretical perspectives underlying terms such as RLS and reconceptualize what it might mean for a language to be maintained and survive without intergenerational mother tongue transmission. As an increasing number of communities around the world face the impending loss of their languages, it is imperative to clarify these issues not just for theory's sake, but in the interest of providing sound advice.
\end{abstract}

KEY WORDS: Language revitalization, diglossia, intergenerational transmission, language shift

ABBREVIATIONS: RLS - Reversing Language Shift; X/Xish - Language undergoing shift; Xmen - Speakers of language undergoing shift; Y/Yish - Dominant language; $\mathrm{H}$ - High language; L - Low language; GIDS - Graded Intergenerational Disruption Scale; ELTSP - English Language Teaching Support Programme

\section{INTRODUCTION}

Over the last decade or so a growing variety of books, scholarly articles and media reports have predicted an alarming decline in the number of languages (e.g. Abley, 2003; Crystal, 2000; Dalby, 2003; Krauss, 1992; Nettle \& Romaine, 2000; Robins \& Uhlenbeck, 1991). Some linguists think that as many as $60-90 \%$ of the world's 6,800 some languages may be at risk of extinction within the next 100 years. Nettle and Romaine (2000: 2) estimate that about half 
the known languages in the world have disappeared over the past 500 years. Crystal (2000) suggests that we may be losing one language every two weeks. Krauss (1992) believes that only the 600 or so languages with the largest numbers of speakers (i.e. more than $100,000)$ may survive. If this is true, few of the 6,000 or more remaining languages will have a secure future. No children are learning any of the nearly 100 native languages in what is now the state of California. Only a handful of the hundreds of Aboriginal Australian languages may survive into the next century. Similar dismal statistics and gloomy prognostications are found all over the globe.

The prospect of the loss of linguistic diversity on such a large scale has prompted a variety of responses ranging from those who find it a cause for celebration (e.g. Malik, 2000) to those who have argued for preserving, protecting and revitalizing threatened languages in various ways (see Romaine, forthcoming for discussion of the assumptions underlying these responses). For those in favor of the latter approach, it is not entirely clear what conditions best support the survival and maintenance of linguistic diversity, and how these might be brought about where they do not currently exist. Fishman's (1991) book devoted to 'reversing language shift' (RLS) promises in its subtitle "theoretical and empirical foundations of assistance to threatened languages". To understand how to reverse language shift, we must first understand how it takes place, and conversely, how it is that languages are maintained. Fishman has devoted most of his professional career to doing just that. However, despite his very substantial achievements and indefatigable activism, I think that we know much more about shift than about reversing it; that is to say, we understand more about how diversity is lost than about how it is maintained.

Fishman (1991: 113) explains why theory is essential:

Stressing the wrong priorities is a very costly example of lacking a proper social theory or model of what RLS entails... The sociolinguistic landscape is littered with the relatively lifeless remains of societally marginalized and exhausted RLS movements that have engaged in struggles on the wrong front (or on all ... fronts simultaneously), without real awareness of what they were doing or of the problems that faced them.

The achievement of intergenerational transmission in the context of stable diglossia is at the heart of his practical advice to communities engaged in reversing language shift. As Fishman (1991: 113) puts it: "Without intergenerational mother tongue transmission, 
... no language maintenance is possible. That which is not transmitted cannot be maintained."

Although I share Fishman's concerns about the survival of languages, I have serious doubts about whether his framework is an appropriate model for the stabilization of endangered languages or for their eventual revitalization as fully functioning native languages. If my reservations are correct, we need to question the assumptions and theoretical perspectives underlying terms such as 'RLS' and 'language revitalization' and to reconceptualize what it means for a language to be maintained and survive without intergenerational mother tongue transmission. ${ }^{1}$ As an increasing number of communities around the world face the impending loss of their languages, it is imperative to clarify these issues not just for theory's sake, but in the interest of providing sound advice to communities who seek linguists' help. A lot is at stake for we are producing knowledge that has potential impact on real world politics and significant consequences for peoples' struggle for self-determination. In doing so, we will also need to be mindful of what I have called elsewhere the 'future of the past' (with acknowledgment to Stille, 2002, from whom I have borrowed the phrase), and whether in the future linguistic diversity will be sustained by quite different patterns of reproduction than it has been in the past (Romaine, forthcoming).

In what follows, I will examine first the relationship between language shift and RLS as conceptualized within Fishman's paradigm. Then I will discuss some of the difficulties in applying the concepts of diglossia and domain theory underpinning the RLS model to the problems faced by many endangered language communities.

\section{The Relationship between Shift and Reversing LANGUAGE SHIFT}

In its simplest terms, language shift may be thought of as a loss of speakers and domains of use, both of which are critical to the survival of a spoken language. The possibility of impending shift appears when a language once used throughout a community for everything becomes restricted in use as another language intrudes

\footnotetext{
${ }^{1}$ My remarks apply to spoken languages. Circumstances are otherwise for signed languages, which are usually transmitted outside the home in institutional settings (see Villanueva, Bishop, and Meyer, forthcoming).
} 
on its territory. Usage declines in domains where the language was once secure, e.g. in churches, workplaces, schools and most importantly, in homes, as growing numbers of parents fail to transmit the language to their children. Fluency in the language increases with age, as younger generations prefer to speak another (usually the dominant societal) language.

Using Fishman's schema of $\mathrm{X}$ to refer to the language undergoing shift and $\mathrm{Y}$ to refer to the language that is replacing $\mathrm{X}$, we can conceptualize the process of shift in the diagram in Table 1. Similarly, we can represent reversing language shift as its mirror image, a kind of role reversal, where $\mathrm{X}$ reclaims the domains it has lost to Y. XY and YX would represent stable diglossia. X and Y appear in upper case to indicate that diglossia is stable; each language has its own set of functions and space without threatening the other. Lower case (e.g. Xy, $\mathrm{xY}, \mathrm{Yx}, \mathrm{yX}$ ) symbolizes that $\mathrm{x}$ or $\mathrm{y}$ is dominated by the other language, $\mathrm{X}$ or $\mathrm{Y}$ respectively.

Some problems with this schema are already evident. The term 'RLS' is misleading as it seems to suggest that we are undoing or reversing the past when it is obvious that we cannot go back in time. The idea of a linear irreversible history is rooted in modern western conceptions of time (Fabian, 1983). It is this western notion of time's arrow pointing forward to which De Fréine (1965: 263-264) refers when he writes that, "history does not go round in circles... history progresses." I have put the last two states of RLS in parentheses to indicate that RLS does not necessarily mean going back to a stage where $\mathrm{X}$ reclaims the majority of domains (i.e. $\mathrm{yX}$ ). Nor is it the case that all X-men (to use Fishman's terminology) will come to speak Xish as their native language, as they did in the past. It most certainly does not entail returning to monolingualism in $\mathrm{X}$.

This point has been misunderstood by some popular critics, as well as by some activists. Malik (2000: 17), for instance, criticizes campaigns supporting linguistic diversity as having

TABLE 1

Language shift and reversing language shift.

\begin{tabular}{ll}
\hline Language shift & $X>X y>X Y>x Y>Y$ \\
Reversing language shift & $Y>Y x>Y X>(y X)>(X)$ \\
\hline
\end{tabular}

$\mathrm{X}=$ shifting language, $\mathrm{Y}=$ replacing language. 
much ... in common with reactionary, backward-looking visions [that] seek to preserve the unpreservable, and all are possessed of an impossibly nostalgic view of what constitutes a culture or a 'way of life'... it is modernity itself of which Nettle and Romaine disapprove. They want the peoples of the Third World, and minority groups in the West, to follow 'local ways of life' and pursue 'traditional knowledge' rather than receive a 'Western education'. This is tantamount to saying that such people should live a marginal life, excluded from the modern mainstream to which the rest of us belong. There is nothing noble or authentic about local ways of life; they are often simply degrading and backbreaking.

Needless to say, Nettle and I don't endorse the view Malik attributes to us. We don't think "sulking on your own rock is a state worth preserving", as he puts it.

Malik and others of this persuasion are very much in synchrony with a view of modernism that anchors societies to different historical points aligned on a single linear trajectory from a traditional past to a modern present according to the extent of their socioeconomic and political development. The opposing ends of the developmental pathway get reified in terms such as 'developing' vs. 'developed' countries and ideological constructions of the languages spoken in such settings derive their perceived values in terms of these oppositions. Romaine (1999) illustrates how conceptions of languages are ideologically linked to and entangled with other dualities (e.g. nature/culture, masculine/feminine, primitive/civilized, indigenous/foreign, intuitive/rational, sentimentality/practicality, backward/modern, rural/urban, pagan/Christian, sacred/profane, etc.) in ways that provide the underpinnings for language shift. In Europe, for instance, languages such as German, English and French became symbols of modernity, in particular of the newly emergent nation-states, at the same time as they were associated with urbanity, finery and higher social status while other languages within their territories such as Scottish Gaelic and Breton became minoritized and stigmatized. Ironically, in jettisoning their own languages and embracing the dominant language, minority language speakers brought about the restriction of their vernaculars to those spheres of church, family and domestic life in terms of which the dominant discourse had, in effect, already characterized the whole culture. The present day diglossic distribution of many minority languages vis-à-vis dominant languages comes then to confirm the imagery as it polarizes these metaphorical dualities along an axis between two societies as represented by their languages.

Thus, terms such as 'traditional' and 'modern' derive their power from this arrangement of events/peoples/societies in a linear 
chronology. Yet, the arguments Malik and others adduce in support of them do not speak for themselves when removed from the context of the master narrative in which they are embedded. As Antonio de Nebrija, Bishop of Avila, remarked in the prologue of his grammar of Spanish (1492), the first grammar of a modern European language, "language has always been the companion of empire". Although language continues to be the companion of empire in the emergent post-colonial world order, its imposition derives less from military force and conquest than from economic control of world markets. English of course in its guise as the world's most important language of the post-industrial global village is seen as the epitome of a modern language. The rhetoric of English as the language of the oppressor has shifted to one in which English is perceived as the language of development and freedom.

For their part, however, many language activists do hark back to an imagined glorious past where their language was vibrant and they may long for the restoration of a society uninterrupted by another language and culture. As Fabian (1983: 11) observes, the posited authenticity of the past serves to denounce an inauthentic present. The discourse of authenticity is basically an essentializing one at the same time as it is oppositional; what is constructed as authentic is about whatever is different from the dominant culture. Brown (1998: 44), for instance, reflects on some of the potentially dangerous implications of a widely held view in Guatemala among Mayas and non-Mayas alike that considers 'true' Indian culture to consist only of those features surviving from the pre-Conquest period. Centuries of exposure to European and African culture are seen as 'contamination' and the incorporation of non-Mayan elements is regarded as a weakening or polluting of Mayan culture. One implication of these views is that the survival of 'true' Indian culture hinges on the impossible historical task of recuperating what has been, to a large degree, irretrievably lost. Another is that to become 'authentic', Mayas today must reject most of what has been going on in the world for the past 500 years as though they had no valid stake or claim in it. The Maya are thus essentially barred from successful participation in the contemporary world or risk being branded as sellouts, traitors or separated from their culture. In the context of language revitalization the discourse of authenticity has been divisive in many communities and led to battles over the use of loan words, debates about orthography, etc. (see e.g. Hornberger \& King, 1999; Romaine, 2002b.) 
This craving to re-establish connections with a supposedly pure and monolingual pre-Hispanic past has its counterparts in other minority language communities. O'Rahilly's (1932: 121) remarks about Manx come to mind:

From the beginning of its career English influence played havoc with its syntax, and it could be said without some exaggeration that Manx is merely English disguised in a Manx vocabulary. Manx hardly deserved to live. When a language surrenders itself to foreign idiom and when all its speakers become bilingual, the penalty is death.

In the Irish context, however, De Fréine (1965: 245-246) warned that:

There can be little justification for the language revival if it is merely an attempt, motivated by mistaken pride, to restore a vanished past. There may be a lot to be said for it, however, if it is viewed as an attempt, grounded in realistic humility, to provide for the exigencies of the future.

Fishman (1991) introduced the notion of GIDS (Graded Intergenerational Disruption Scale), an eight-point scale characterizing the extent to which a particular language is endangered, in order to provide a means of assessing the extent to which transmission of a language has been disrupted. He intends it as a heuristic device to assist communities in targeting their efforts to specific activities needed at each point of the scale. This follows from his view that language maintenance is not "a global 'total language' task", but rather a "functionally specific process which must be tackled on well-chosen, functionally specific grounds" (Fishman, 1991: 65). (Table 2)

Fishman furthermore divides GIDS into two sets of four stages. The first set comprising stages (8-5) is characterized as "RLS on the "weak side': in pursuit of diglossia" (Fishman, 1991: 396), and the second set comprising stages (4-1) is termed "RLS on the strong side, or transcending diglossia in search of increased powersharing" (Fishman, 1991: 401). RLS on the weak side aims primarily to establish intergenerational transmission, whereas RLS on the strong side aims to introduce the minority language into various institutions. Stage 6 is the crux of RLS because only intergenerational transmission secures maintenance. Stages 8-6 are labor intensive rather than cost intensive in that they depend on the ability of individuals and communities rather than external agencies such as governments or education systems.

For Fishman then, the attainment and maintenance of what he calls 'stable diglossia' in the first instance is seen as the key to 
TABLE 2

Fishman's Graded Intergenerational Disruption Scale (GIDS), adapted from Fishman (1991).

\begin{tabular}{|c|c|}
\hline Stage 8 & $\begin{array}{l}\text { Most vestigial Xish users are socially isolated and Xish needs } \\
\text { to be reassembled from their mouths and memories and taught } \\
\text { to demographically unconcentrated adults }\end{array}$ \\
\hline Stage 7 & $\begin{array}{l}\text { Most Xish users are a socially integrated and ethnolinguisti- } \\
\text { cally active population but are beyond child-bearing age }\end{array}$ \\
\hline Stage 6 & $\begin{array}{l}\text { The attainment of intergenerational informal oracy and its } \\
\text { demographic concentration and institutional reinforcement }\end{array}$ \\
\hline Stage 5 & $\begin{array}{l}\text { Xish literacy in the home, school and community, but without } \\
\text { taking on extra-communal reinforcement of such literacy }\end{array}$ \\
\hline Stage 4 & $\begin{array}{l}\text { Xish in lower education that meets the requirements of } \\
\text { compulsory education laws }\end{array}$ \\
\hline Stage 3 & $\begin{array}{l}\text { Use of Xish in the lower work sphere (outside the Xish } \\
\text { neighborhood/community) involving interaction between } \\
\text { Xmen and Ymen }\end{array}$ \\
\hline Stage 2 & $\begin{array}{l}\text { Xish in lower governmental services and mass media but not in } \\
\text { higher spheres of either }\end{array}$ \\
\hline Stage 1 & $\begin{array}{l}\text { Some use of Xish in higher level educational, occupational and } \\
\text { media efforts (but without the additional safety provided by } \\
\text { political independence) }\end{array}$ \\
\hline
\end{tabular}

minority-language maintenance and even reversal of language shift within multilingual speech communities. When diglossia is stable, each language has its own set of functions and space without threatening the other. Bilingualism without diglossia tends to be transitional and the predicted outcome of such situations is language shift (Fishman, 1967: 36). From Fishman's perspective, the future of minority languages would be problematic without sharp functional compartmentalization of codes and without the most stubborn maintenance of voluntary boundaries between the dominant and minority language speakers and their cultures.

Ten years after the publication of the 1991 book, Fishman (2001) published a second book, whose title poses the question of whether threatened languages can be saved. Its appearance is timely, given the greater awareness of the threat to the world's linguistic diversity and the growing interest in endangered languages during the interval between the two volumes. In this new book Fishman returns to many of the same threatened languages, whose prospects for survival he considered in the earlier volume. This time, however, he does so as volume editor of a set of 18 studies from around the world rather than as sole author. In his 
reappraisal of the scene 10 years after, Fishman (2001: 478-479) observes that none of the dozen individual cases studied in the late 1980s and early 1990s has experienced "dramatic successes". Indeed, his overall conclusion is very much an ambiguous one: although the general climate of opinion to threatened languages has improved "in an amorphous and largely still ineffectual sense", the prospects for reversing language shift have not improved much and have even deteriorated (Fishman, 2001: 480). Naturally, there are many reasons why that is the case, as the individual chapters show, and time does not permit me to detail all the observations made there. Needless to say, no single factor emerges as the unique cause of either success or failure. A complex set of interlocking political, geographical, cultural and socio-economic factors support the maintenance of linguistic and cultural diversity.

Nevertheless, the case of Yiddish in New York City presents a fascinating and perhaps uniquely instructive opportunity to examine the fate of a language embedded in two contrasting social settings. ${ }^{2}$ Ten years on, Fishman (2001: 97) says that Yiddish is stronger now in Ultra-orthodox communities, while it is weaker among the secularists, in the face of the impending loss of the last remaining elderly native speakers. From this he concludes that the barriers erected by fundamentalism may

provide a much clearer boundary maintenance pattern for RLS than modernisation ever does or could do, particularly in the face of American controlled globalisation, consumerism and mass pop-culture. The triumph of the ultra-Orthodox 'ugly duckling' is a Cinderella story seemingly made to order for RLS efforts on behalf of threatened languages (Fishman, 2001: 98).

In what sense is this scenario made to order for most of the world's small language communities? Although the case studies offered here are varied and rich in detail, inevitably they represent a mere handful, and a highly select handful at that. If the projections of endangerment based on size in sources such as Nettle and Romaine (2000) are correct, then as many as $60 \%$ of the world's languages are spoken by communities with fewer than 10,000 speakers and may be at risk. Only 3 of the case studies in this volume

\footnotetext{
2 Another such instance can be found in Burridge (2002), who contrasts the fate of varieties of Pennsylvania German, some of which have survived alongside English for nearly 400 years among certain Mennonite communities. Degree of religious conservatism corresponds with extent of competence in German. Among the most conservative groups such as the Old Order Mennonites there is a strict and stable situation of diglossia with bilingualism and no mixing. Among other less conservative groups, as soon as English intrudes into what were German domains, shift to English is swift and complete.
} 
(namely, Andamanese with around 35 speakers, Ainu with 30, and the strongest Australian Aboriginal language, Warlbiri, with around $3,000)$ are representative of small language communities.

French in Quebec has emerged as a symbolic case "for language minorities of the world, for it shows that sustained language planning can reverse language shift even relative to the most powerful language of this millennium: English" (Bourhis, 2001: 101). Yet most small language communities can only wish for such an enviable position of strength from which to launch RLS efforts. Moreover, Bourhis (2001: 105, 111) says that language planners in Quebec were well placed to intervene in the 1970s in favor of French with strong intergenerational transmission on their side, even though a sociolinguistic analysis would have led to the conclusion that such planning was unnecessary. More than $80 \%$ of the population had French as a mother tongue and more than three quarters were monolingual French speakers. In addition, Francophones controlled most of the provincial administration, even though they lacked control of the major business and financial institutions. It was the threat to French survival in the long term in the face of declining birthrate and increased immigration of Anglophones and others likely to assimilate to the Anglophone population that provided the ideological impetus to mobilize. Few communities are concerned about language transmission when all is proceeding normally, and even when it is not, various factors impede recognition of the impending loss and its consequences.

Hence, it is unclear what guidance and hope these studies offer to the majority of the world's small languages. In fact, even among the much larger language communities examined, it is hard to find an example of a RLS movement which has followed Fishman's advice of securing home transmission and attaining stable diglossia before proceeding to higher levels. It is instructive to examine Hebrew, another of his success stories from the 1991 volume, and the case most frequently offered in popular accounts and by many activists as proof that a 'dead' language can be revived. Nevertheless, the circumstances surrounding Hebrew are perhaps unique and often not properly understood by activists who have looked to it as a model for their own languages. Hebrew of course was dead only as a spoken vernacular; it remained in active use as a literary and religious language. The account given by Fishman (1991) for the revitalization of Hebrew does not follow the GIDS model. Stage 5, which involves literacy at home, school and community, preceded 
Stage 6 by more than 1,000 years (Spolsky \& Shohamy, 2001: 354). ${ }^{3}$

Fishman has nevertheless been quite insistent about the necessity of proceeding from the bottom up, and of securing Stage 6 before proceeding to higher levels. One of the most frequent mistakes activists make is to attempt to reverse the diglossic hierarchy by promoting the minority language in the domains now dominated by the majority language. What often results from active intervention to reverse language shift is a reversal of domain distribution in $\mathrm{H}$ [igh] (seen as equivalent to $\mathrm{Y}$ in Fishman's model) and L[ow] (equivalent to $\mathrm{X}$ ), with a decrease in the use of $\mathrm{L}$ at home and in private domains, and an increase in its use in public, formal domains such as government, education, etc. The net result is that $\mathrm{L}$ is forced to compete with $\mathrm{H}$ in virtually all domains. Although the failure of such efforts to restore intergenerational transmission appears to validate Fishman's theory, there are some rather more fundamental problems at stake in his use of diglossia as a frame of reference.

\section{Problems with Diglossia as a Frame of Reference in RLS}

A number of sociolinguists have criticized the notion of diglossia and the related concept of domain for being more of a hindrance than a help in analyzing language contact. Williams (1992), for instance, criticizes both Fishman and Ferguson (1964), and indeed most of contemporary sociolinguistic theory, for stressing the consensual nature of such arrangements rather than the dimensions of power and conflict underlying them. Likewise, Calvet (1993: 45) criticized the concept of diglossia for tending to "obfuscate the conflicts that characterized diglossic situations and to present as normal a situation of domination." As Martin-Jones (1989: 109) suggests, viewing diglossia as a language maintenance strategy represents this division of labor as a natural form of social and linguistic order, and thus implicitly reinforces the legitimization of the $\mathrm{H}$ language. We cannot, therefore, adopt diglossia itself as the aim of language maintenance because it can promote inequality and contribute to language shift. Even if the balance of power seems stable, diglossia is not so much a force of stability as a reflection of

\footnotetext{
${ }^{3}$ Shohamy (forthcoming) offers a more penetrating and critical analysis of the extent to which the legitimation and institutionalization of Hebrew was accomplished at the expense of immigrant languages.
} 
transitory unequal balance of power between dominant and minority languages (Eckert, 1980).

The essence of these criticisms then is to claim that in so far as the diglossia that Fishman is so concerned to stabilize is in effect a symptom of the unequal balance of power between languages, diglossia is something to be overcome rather than to be attained. Black $(1990,1993)$ accuses Fishman of attempting to 'reverse language shift' at the cost of empowerment of minority language speakers, in particular, Aboriginal Australians, for whom domain separation can be damaging in the long term. He argues that language extension has a greater potential for language maintenance. Likewise, McConvell (1992: 216-217) points out that the struggle for power in institutions is part of the struggle for power to use Aboriginal languages in government and community agencies controlled by dominant language speakers. Gaining a voice in such spheres of political power may give Aboriginal speakers greater ability to promote policies fostering increased use of their language in other sectors.

Williams proposes that sociolinguistics should dispense with the term 'diglossia' altogether because the domain segregation found in diglossia is nothing more than a manifestation of the power differential between $\mathrm{H}$ and $\mathrm{L}$. This is perhaps to throw out the baby with the bath water. I think the term 'diglossia' is still useful in a narrow sense to refer to a particular configuration of relationships of functional specialization between two varieties (Romaine, 2002a). My arguments, however, against its utility in a viable model of language maintenance and shift are of a different nature. Diglossia and societal bilingualism are not surface variants of the same underlying phenomenon, but are fundamentally different in their social origins, evolutionary course of development, and resolutions over the long term. Thus, the inclusion of these two sociolinguistic arrangements under the single rubric of 'diglossia' obscures rather than clarifies sociolinguistic theory (see Hudson, 2002).

Imbalance of power is the key feature that distinguishes diglossia from societal bilingualism. Yet, emphasizing instead the asymmetric functional differentiation of codes as the common denominator of a variety of sociolinguistic arrangements to which the concept has been extended has resulted in the merger of fundamentally distinct situations. Much hinges in this debate on the weight assigned to the defining features of diglossia. Which is most 
important? Does the alleged relative stability of diglossia derive from the fact that no one uses the $\mathrm{H}$ variety for normal conversation? Or does the functional distribution of varieties protect the role of L as a natively learned variety? In Ferguson's original model, only $\mathrm{L}$ is acquired as a natural mother tongue, a fact that is usually overlooked as a critical feature of diglossia. The superposed variety $\mathrm{H}$ is a learned variety, not a primary one. The typical fate of diglossia, which has tended to decline with the spread of modernization, urbanization, mass education, literacy, etc., is that the $\mathrm{H}$ variety is weakened under pressure from an emerging new social order in which increased power is given to previously marginal groups. When diglossia becomes unstable, shift is anticipated to occur from $\mathrm{H}$ to $\mathrm{L}$ in formal domains of interaction or from $\mathrm{H}$ to a new vernacular-based standard rather than from $\mathrm{L}$ to $\mathrm{H}$ in informal domains. In language shift, on the other hand, $\mathrm{H}$ usually succeeds in eliminating $\mathrm{L}$ from all its former domains, with the home often the last to give way to $\mathrm{H}$.

Still, it is far from obvious whether the long term maintenance of a vernacular necessarily follows from a functional compartmentalization of codes or whether its loss follows from the absence of such compartmentalization. It is the particular social etiology of diglossia which explains the security of $\mathrm{L}$ as vernacular over the long term. This makes it an inappropriate model for the stabilization of endangered languages or for their eventual revitalization as fully functioning native languages. The model does not suggest the means whereby such functional compartmentalization might be motivated, attained, and maintained. That is, it would entail the eradication of the $\mathrm{H}$ variety from all domains of personal, informal interaction and therefore from all first language contexts.

Even before Fishman applied his extension of Ferguson's concept of diglossia specifically to the task of RLS in bilingual communities, Pedraza, Attinasi and Hoffman (1980) argued that the model did not provide insight into the dynamics of contact between Spanish and English in the Puerto Rican community in New York City, where they claim that Spanish is being maintained without strict compartmentalization of domains. Observed patterns of bilingual usage suggested inadequacies underlying Fishman's linkage between diglossia and language maintenance and shift. Rather than compartmentalizing their use of Spanish and English, bilinguals were using English in many settings considered to be private and Spanish in many considered public (Pedraza et al., 1980: 88). In addition, 
code-switching, another sign of lack of compartmentalization, was a common mode of interaction.

In earlier work Fishman was careful to claim that "the relationship between bilingualism and diglossia is far from being necessary or causal" (Fishman \& Markman, 1979: 85, 90). Yet at the same time, this disclaimer was undermined by his insistence that separation was causally related to language maintenance. Within the RLS framework Fishman (1991) has been quite specific in his advice to language activists to restore and transmit their language as the first language of the home; only families can make that happen through strict boundary maintenance. Of course, it is no simple matter to reclaim lost domains or to extend the use of $\mathrm{L}$ into new domains. Indeed, as I noted earlier, Fishman (1991) has pointed out that one of the most frequent errors made by activists is to attempt to prop up a language 'from the top down', so to speak, either by restoring the use of the language to $\mathrm{H}$ domains or creating them where they did not previously exist, rather than by strengthening the language from the bottom up. This does little to counteract loss because shift is fuelled by the prestige of those who use $\mathrm{H}$ as a vernacular rather than by the prestige associated with the domains in which $\mathrm{H}$ is used. Not that the prestige associated with high domains is worthless; far from it. As I will argue in the next section, many large language communities are engaged in struggles to keep English from encroaching on their territory in high domains. The most evident feature of any attempt to increase the status of a minority language is that it involves the reinstitutionalization and relegitimation of its domain context which has become disrupted through the intrusion of another language (Williams, 1992: 135). In this respect too, we are not so much reversing the past, but rather renegotiating the various processes that have undermined languages, e.g. modernization, changes in economic conditions, boarding schools, language attitudes.

In diglossia, however, it is context and not the social identity of the speakers that controls use. Thus, the critical distinction between the canonical cases of diglossia and the more typical cases of societal bilingualism resides in the presence or absence of a prestige group of native $\mathrm{H}$ speakers. Some Galician activists, for instance, reject the possibility of achieving stable bilingualism by changing the diglossic relationship between Spanish and Galician under current political conditions in Spain. The official language policy aimed at 'normalizing' Galician, i.e. restoring its use in all 
domains, cannot alter the associations between Galician and Spanish with differing levels of socioeconomic development and cultural prestige. This means that the normalization of Galician cannot proceed except at the expense of Spanish (see del Valle, 2000). Hence the notion of stability is ill-conceived, and it remains to be seen whether diglossic situations are in any sense more stable than other types of sociolinguistic arrangements between two varieties. More important is the likely direction of change once realignment of the codes and their social functions occurs.

Not surprisingly, what often results from active intervention to reverse language shift is a reversal of domain distribution in $\mathrm{H}$ and L. Fishman (1991: 54-55), for example, compares the distribution of Basque and Spanish in 1957 and 1987, noting that over this 30 year period there has been a decrease in the use of Basque at home and in private domains, while there has been a slight increase in the use of Basque in public, formal domains such as government, education, etc. In Wales too, where Welsh has been introduced in public domains where it used to be excluded, e.g. public administration and education, its previous dominance in other critical domains such as the home, and even the chapel in some areas has been weakened (Jones, 1998). The family is no longer the main agency of language reproduction. It has been largely replaced in this role by education. As Jaffe (1999: 23) observes in connection with attempts to use Corsican in public domains, this kind of language activism is clearly derived from the dominant language ideology. It does not disturb or challenge the diglossia schema and its hierarchy of values, but attempts to improve the standing of Corsican within the existing framework. Much of her study is devoted to documenting the dilemmas and unintended social consequences of an ideology of resistance grounded in reversal. Likewise, Woolard (1998: 17) has underlined the irony in the fact that many movements to save minority languages are often structured around "the same received notions of language that have led to their oppression and suppression"; that is, the culture of monoglossia. Both state policies as well as challenges to them are often embedded in nationalist ideologies of language and identity, which is one of the most deeply entrenched ideologies of modernity.

The main point here, however, is not stability, or indeed any particular defining feature of diglossia, but instead the interdependent nature of the features. The functional compartmentalization, acquisition, and stability of $\mathrm{L}$ as a vernacular are causally related. 
An important point often overlooked in this discussion is the fact that the domains occupied by $\mathrm{H}$ are in fact by definition secondary agencies of language reproduction and cannot therefore transmit languages effectively, nor can they replace the home as the primary site and agency of language transmission. As Fishman (1997: 194) points out, "endangered languages become such because they lack informal intergenerational transmission and informal daily life support but, in order to cease being endangered, they need exactly what they do not have and cannot easily get".

Most of what has been achieved in Ireland and many other cases of so-called language revitalization might be thought of as leading instead to increased institutionalization of minority languages, a process which ironically has worked to give more control over the process of language reproduction to the very state agencies which have worked in the past to marginalize these languages and their speakers. The experience of seventy some years of state intervention on behalf of Irish shows that there is an important distinction to be made between learning a language in the artificial environment of the classroom and transmitting it in the natural environment of the home. Schools in Ireland have achieved most of what can be expected from formal language education, namely, knowledge of Irish as a second language acquired in late adolescence. They have not led to its spoken use in everyday life, nor its intergenerational transmission.

With home bilingualism in decline, the pattern is for community use of Irish to be higher than home use. O Riagáin (1997: 107) suggests that contrary to prevailing wisdom, the home may be the first rather than the last domain to exhibit language shift. In the Gaeltacht the historical process of language shift is progressing to the point where Irish is ceasing to be a community language and becoming instead the language of particular social networks. It is to shifts in social network patterns rather than domains per se that Ó Riagáin looks to explain these changing patterns.

More importantly, however, the power of state language policies to produce intended outcomes is severely constrained by a variety of social, political and economic structures which sociolinguists have typically not addressed, even though their consequences are profound and of far more importance than language policies themselves (Ó Riagáin, 1997: 170-171). Similarly, Nettle and Romaine (2000: 79, 179) observe that the first causes in language loss are not themselves linguistic. Where language use changes, there is an 
underlying social upheaval which may have environmental, economic or political causes. The preservation of a language in its fullest sense ultimately entails the maintenance of the group who speaks it, and therefore the arguments in favor of doing something to reverse language death are ultimately about preserving and sustaining viable communities. In a similar vein, Mühlhäusler (2002: 38) has argued for abandoning the notion that languages are in competition, with the implicit belief that languages can be made to survive by making them more competitive, that is by giving them grammars and dictionaries rather than asking how we can preserve or recreate the ecological conditions for linguistic diversity.

\section{The Battle Over High Domains}

There are some signs that revitalization movements underway for a number of decades have begun to confront these sober realities. Benton's (1999: 7) recognition of the fact that "revitalization of the Maori language is primarily a matter of sustainable cultural and economic development" will hopefully spur reconsideration of the larger context in which revitalization inevitably takes place. He questions the New Zealand government's language policy aimed at the use of Maori for "the full range of modern activities" because it is "likely to direct limited resources to marginal but costly activities, to the detriment of smaller, unspectacular, but in the long run potentially much more effective and sustainable developments" (Benton, 1999: 116). More specifically, Benton argues against trying to modernize Maori as a suitable vehicle for science, for example, which requires massive infusion of new abstruse technical vocabulary at the risk of colonizing the language even further and making it a calque of English. "Let English remain the language for Geekdom", he advocates (Benton, 1999: 117); concentrate instead on identifying which institutions in traditional or contemporary Maori society might best support the sustained and sustainable use of the language. This is to recognize, as Fishman (2001: 476) himself has pointed out, that $\mathrm{X}$ has functions it can defend that $\mathrm{Y}$ does not have; these are the logical functions around which to build RLS fortresses.

For some activists this may seem an admission of defeat, tantamount to accepting the claim that a minority language can survive only through separation from the modern world and by remaining 
undeveloped for use in non-traditional domains. Its absence or withdrawal from the public sphere concedes defeat in the struggle for what Fishman calls diglossia on the strong side, or increased power sharing "by surrendering to Yish all effective control over the more modern and interactive media and pursuits" (Fishman, 1991: 400).

Many revitalization efforts underway are in effect recapitulating a path of discovery followed by a number of newly independent nations such as India, Tanzania and Malaysia, where shifting from the colonizers' language to the local vernacular(s) was seen as fundamental for building a new nation out of a former colony. In the context of recommendations for a new post-independence educational framework, Annamalai (2005: 24-15), for instance, notes how subject specialists appointed by the state and federal governments created millions of technical terms in various academic and technical domains, in addition to translations and textbooks, in order to prepare selected Indian languages to take the place of English. He condemns this exercise in language development as a useless project because it is premised on the assumption that to replace English the Indian languages must first become like English to play its role rather than the converse; namely, that Indian languages must first assume the role of English to become like it in the course of practice. Given the exponential increase in the knowledge created in and spread through English, keeping pace with English will always be an impossible task. Hindi still has not replaced English as sole official language as the framers of the Indian constitution intended.

Similarly, in post-independence Tanzania, despite the strides made by Kiswahili in displacing English from most of the high domains it monopolized, the government has repeatedly failed in its attempt to replace English in secondary and tertiary education (Brock-Utne, 2000). Although the policy for making Kiswahili the medium of instruction throughout all the primary grades by 1973-1974 was implemented as planned under then President Nyerere's commitment to rural development grounded in socialist principles, and one of the major tasks of the Institute of Kiswahili Research between 1970 and 1980 was to develop terminology to facilitate the use of Swahili in secondary schools (Abdulaziz, 1988), the government decided in 1983 to stop further expansion of Kiswahili at higher levels in the educational system. Thus came to an end one of the most progressive language policies in Africa. 
The decision to reverse course seems to have been taken by President Nyerere himself, (partly with the support of the British Council) during a period when economic recession was hitting many African countries in the 1980s, and school enrollments were declining after having tripled in the preceding two decades. Nyerere's initial plans were undermined by budget deficits and inflation. As worsening terms of trade gave rise to debts, the World Bank and the International Monetary Fund pressured Tanzania in 1986 into signing an agreement accepting economic structural readjustment programs containing conditions on the liberalization of the economy, a decrease in public expenditures and increasing privatization. In 1966 Tanzania spent $14.2 \%$ of its national budget on education and $8 \%$ on debt servicing; in 1987-1988, the government spent $33.2 \%$ on debt servicing and only $5.4 \%$ on education. In 1992 educational spending fell to 4\%. (Brock-Utne, 2000: 26). The World Bank also advocated more private schools at both primary and secondary education.

In 1985 the British government embarked on funding a ten year program of development assistance called the English Language Teaching Support Programme (ELTSP) to supply English language teaching officers and teaching materials. Although this was the most costly aid project ever funded by the British Overseas Development Administration, an evaluation of the program's outcome concluded that "the original aim of improving secondary education simply through an English language support programme must be regarded as naive" (Gilpin, Garrett, Kapinga, \& Kanyelele, 1996: 7). The report found no evidence, either anecdotal or empirical, to indicate "any general improvement in examination results across the curriculum." (Gilpin et al., 1996: 6). Sadly, the ELTSP had been prompted by an earlier evaluation done in 1984 that found levels of English at most schools too low for effective learning to take place. Criper and Dodd (1984) stated categorically that English had ceased to be a viable medium of education. Yet, instead of lending support to the government's original plan to expand the use of Kiswahili, Criper and Dodd offered the disease as the cure. They recommended that the British government fund the ELTSP on condition that English continued to be the medium of instruction.

As recently as 1997 the Tanzanian government reset the original target dates of 1985 for change from English to Kiswahili for secondary schools, and of 1992 for university level, in a policy 
statement that reiterated implementing Kiswahili as the medium of instruction at all levels. Teaching in Kiswahili in secondary schools was to commence in 2001, but this new target date has come and gone. In the most recent versions of the constitution the issue of language is not mentioned. Meanwhile, not surprisingly, private English-medium schools have been increasing at both primary and secondary levels at the same time as the level of English proficiency continues to decline. Brock-Utne (2000: 38) mentions that Nyerere later regretted not following through with his plans to strengthen Swahili, and she is critical of alliances between donors, economic and intellectual elites that make it hard for governments to embark on language policies of their choice. Similar shifts toward reinstating colonial languages have affected other countries too. Madagascar, for example, has for many years succeeded in having Malagasy as a language of instruction, but in 1988 the government reintroduced French medium education in secondary schools, a move that was supported by development aid from France in the form of textbooks.

Canagarajah (2005: 196) observes how globalization has pulled the carpet out from under the feet of developing countries just as they began undergoing decolonization. While decolonization entailed rejecting colonial languages, globalization intensified and renewed the need for them. As the world's only truly global language, English is paradoxically positioned as both the key to and an obstacle to development. In 2003 the Malaysian government implemented a policy to switch from Malay to English as the medium of instruction in science and mathematics after having spent four decades putting considerable financial resources into modernizing Malay. Gill (2004) compares the number of translations into Malay produced during that time (ca. 650) with the virtual explosion of scientific publication in English, where according to statistics cited by Martel, 2001: 51) there are over 100,000 scientific journals in the world publishing articles at the rate of 5,000 per day, most of them in English.

Schiffman (forthcoming) observes in his discussion on scientific terminology and registers that any language can come up with an equivalent for mad cow (disease) (cf. French vache folle, etc.) but finding an equivalent for the technical term transmissible spongiform encephalopathy (TSE) is another issue (cf. however, French l'encéphalopathie spongiforme bovine), especially in non-western languages. Those who develop science also develop the register for 
discussing it. A scientist working in another language who wanted to do research on TSE cannot afford to expend time translating these terms and finding suitable 'native' terminology; their time would be better spent doing research on TSE, not on the terminology. If scientists try to keep up with the terminology development, they fall behind in the science. Schiffman argues that reliance on English for science and technology means that diglossia between English and other languages in countries such as India will probably continue to be maintained and reinforced.

Although I am sympathetic to Schiffman's argument, I still think that there is a distinction to be made between technical and specialized communication between scientists at the international level and the communication of scientific knowledge to students and the general public. The production of scientific knowledge cannot and should not be restricted to a few languages, let alone just one, i.e. English, if the true human potential for creativity is to be expressed. There is a vast amount of largely undocumented scientific knowledge in the world's indigenous languages. When this knowledge is lost, it becomes increasingly difficult even to frame problems and solve them in any but the dominant culture's terms and scientific classification schemes, which are not always adequate to the task. What goes by the name of modern science is based largely on the worldviews, priorities, and perspectives of Europeans and their languages, especially English (Nettle \& Romaine, 2000: 77). Still, it is difficult to break out of the self-reinforcing cycle of increasing intellectual dependency whereby languages such as Hindi and Kiswahili do not develop as languages of science because they are not being used and the argument that they cannot be used because they are not developed.

Even speakers of recently modernized and much larger languages such as Turkish, not to mention those of many small European languages such as Dutch, feel that the continued use of their languages in technical domains and in many areas of higher education is threatened by English. In South Africa what has become known as the taaldebat ('language debate) is being waged over maintaining the higher functions of Afrikaans, particularly in higher education in the wake of the post-apartheid government's new multilingual policy in which Afrikaans no longer shares an equal place with English as co-official language, but is one of eleven official languages. English and Afrikaans are joined by nine indigenous African languages. Numerically, all of these are minority languages 
in that none claims a majority of the population of 45 million. English is spoken by about 3.7 million, while Afrikaans is spoken by nearly six million people, the majority of whom are not white, and live in the Western Cape province. The largest African language, Zulu, has about nine million speakers.

One of the primary battlegrounds for the debate is Stellenbosch University, historically one of five white Afrikaans-medium universities in the country. Founded in 1918 to serve the cause of Afrikaners and one of the main intellectual sources of apartheid, it was at Stellenbosch that Afrikaans was transformed from "a local patois into a language of literature and science" (Brink, 2006: 1). The post-apartheid government's National Plan on Higher Education decreed a restructuring of universities with a view to eliminating language barriers, noting in particular that the notion of "Afrikaans universities" ran counter to the goal of a transformed higher education sector (Brink, 2006: 17). While other historically Afrikaans universities amalgamated with other institutions and/or adopted bilingualism, Stellenbosch remained the last all-Afrikaans institution.

In 2002 a newly formulated policy (under review in 2006) aimed to promote Afrikaans as a language of teaching and science in a multilingual context; English and Afrikaans are both used in the Faculty of Arts. Giliomee and Schlemmer (2001) have argued that protecting the use of Afrikaans at tertiary level is crucial to its survival as a 'public language' with higher cultural functions; in their view a language without higher functions is a second-rate and seriously endangered language. To this end, they argued that an Afrikaans-only policy should be implemented and strictly enforced at Stellenbosch. Brink (2006: 76), however, sees the debate as an attempt to reposition Afrikanerdom as an endangered minority within a liberal democracy led by "neo-Afrikaners" who are seeking to rebuild Afrikaner nationalism and an Afrikaner identity around Stellenbosch as their rallying point and home. He suggests that the way forward is to disengage Afrikaans from the ideology and identity of white Afrikanerdom (Brink, 2006: 141). However, beyond that looms the question of what the inability of Afrikaans to retain its higher functions in the public domain has to say about the likelihood of the African languages attaining them.

With English rapidly becoming the first preferred foreign language study at school in the European Union, and in most other parts of the world, most people in northern European countries are 
becoming bilingual in English at an increasingly earlier age through schooling. Soon there will be few monolinguals among their schoolage populations. Excluding Britain and Ireland, 92\% of secondary school students are studying English, nearly three times the number studying French and seven times the number studying German (Eurydice, 2005). In today's global village increasing bilingualism in a metropolitan language, particularly English, is making the majority of the world's languages in effect minority languages. Even small national languages such as Icelandic with its 290,000 speakers, and larger national languages such as Swedish and Hebrew, substantially protected by political boundaries and institutions, are dominated by English at the highest levels of international communication.

At this juncture, we need to return to some of my earlier remarks about how the ideology of monoglossia has underpinned state language policies as well as the activism of many RLS movements. In addition, a binary model of diglossia cannot adequately account for the complexity of the sociolinguistic situation in India, Tanzania and Malaysia, which are among the world's most linguistically diverse countries, with 415, 128 and 140 languages respectively, according to Ethnologue (Gordon, 2005). Yet, as Dua (1994: 85) observes, India's constitutional provision for Hindi to replace English after fifteen years was unrealistic. For one thing, it assumed that Hindi could achieve in a few years what English had achieved over the course of a century. Most importantly, however, the provision was grounded in the premise that Hindi would replace English in an elitist monolingual model where the role of India's 'other' languages was to be subservient to Hindi, just as Hindi was/is to English. Similarly, in Tanzania the sociolinguistic situation involved what some sociolinguists have variously described as triglossia, polyglossia or double-nested and/or doubleoverlapping diglossia (see Fasold, 1984: Chapter 2). Overall, the domains of use for English have shrunk since Kiswahili was officially designated the national language (along with English) when the country became independent in 1962, but the spread of Kiswahili was strengthened at the expense of the indigenous languages spoken by the majority of rural poor (see Rajabu \& Ngonyani, 1994 for a more nuanced perspective on the relationship between Kiswahili and English).

What do these experiences of large language communities have to say to the language planning efforts on behalf of Maori and 
other small languages when even a very large language such as German, now the most widely spoken language in Europe, has retreated considerably as an international language of science (Ammon, 2001)? Even if planners ignore the demand for lexical elaboration to keep pace with science and technology, is it the case that "success in intergenerationally unimportant functions is merely camouflaged failure"? (Fishman, 1991: 86). The answer to this question presupposes addressing the question I raised at the outset about whether linguistic diversity will be sustained in the future by quite different patterns of reproduction than it has been in the past.

\section{The Future of the Past}

What then is the future of the past as far as linguistic diversity is concerned? Fishman's conception of RLS is narrowly focused in its specific aims at the same time as it is broad in scope. Its focus is narrow in the sense that everything that does not lead to the restoration of intergeneration transmission is merely camouflaged failure and amounts to biding time (Fishman, 1991: 86, 399). Its scope is broad in that RLS involves nothing short of cultural reconstruction and community building through the threatened language (Fishman, 1991: 17). As Fishman (2001: 452) has put it more recently, "RLS is concerned with the recovery, recreating and retention of a complete way of life, including both non-linguistic as well as linguistic features."

It may be more realistic, however, to recognize King's (2001: 26) distinction between RLS and language revitalization, which can be understood as not necessarily attempting to bring the language back to former patterns of familial use, but rather to bring the language forward to new users and uses. In doing so, however, we must not deceive ourselves that the efforts directed at the latter will restore intergenerational transmission. There may be an increase in users and uses of language without intergenerational transmission. Spolsky (2003: 554-555) has recently proposed that in addressing the question of success or failure of Maori efforts we need to 'desynonymize' a number of terms often used interchangeably. $\mathrm{He}$ prefers the term 'regeneration' for activities that increase the status and salience of a language, and reserves 'revitalization' for the restoration of intergenerational transmission. His perspective on Maori sees it not as an instance of language loss followed by 
attempts to reverse language shift, but as the continuation of a long process of negotiation of accommodation between Maori and English. Whatever proposals we adopt regarding terminology, I think it is important to take the step of uncoupling the notions of maintenance and intergenerational transmission. This means revising our notions of what it means for a language to 'survive' without home transmission.

In putting the onus on restoration of intergenerational transmission at home as the sole criterion of success, we run the risk of dismissing the value of the journey, which is at least as, if not more, important than the endpoint, as long as each step is regarded as valuable to the community concerned. Although Fishman (2001: 477-478) himself believes that there will always be functional space for smaller languages, he still regards the belief that 'anything is better than nothing' as a mistaken RLS path. Dauenhauer and Dauenhauer (1998: 97), however, write that

it is unrealistic to expect the Native languages of Southeast Alaska to recover fully and thrive as they did sixty to a hundred years ago. But they can continue to be used in many ways, both oral and written, that are of enduring spiritual value to the individual and the community, even if these new uses are far more limited and restricted than they would have been in the past.

For Littlebear (1999: 1), the spiritual value of native American languages is paramount:

But why save our languages since they now seem to have no political, economic or global relevance? That they seem not to have this relevance is exactly the reason why we should save our languages because it is the spiritual relevance that is deeply embedded in our own languages that is important. The embeddedness of this spirituality is what makes them relevant to us as American Indians.

In so far as these new uses that King and others refer to may fall short of what is required in practical terms to guarantee intergeneration transmission, the main value for many small languages in the future may well be symbolic and cultural rather than practical. That is to say, many will not be widely used, if indeed at all, in everyday communication; they will cease being grounded in continuity of practice, and instead become primary vehicles for the articulation of identity.

If this is the case, then we are confronting the possibility of forms of transmission and maintenance unlike those which prevailed in the past. Many languages are already surviving without their customary heartlands that once served as a resource base for transmission. The profile of those who speak $\mathrm{X}$-ish is now 
radically different in many communities actively engaged in revitalization. This is because these new speakers are products of secondary agencies of transmission rather than of reproduction (Williams \& Morris, 2000). More children are learning Basque through the education system than are learning it at home as a native language. Among the youngest sectors of the population, those who have learned Basque as a second language already outnumber native Basque speakers. The same is true of many other cases. The maintenance of more or less stable rates of bilingualism over recent decades in Ireland has been due more to the capacity of the schools to produce competent bilinguals than to the capacity of the bilingual community to reproduce itself (ÓRiagáin, 2001: 204). Thus, the notion of 'Basque' or 'Irish speaker' is undergoing a radical transformation as a result of significant qualitative changes in the Basque-speaking and Irish-speaking populations. These new speakers are very different with respect to fluency and the density of Basque or Irish speakers in their networks. This has an enormous influence on their language use, as well as on the languages themselves (Hornsby, 2005; Jones, 1998; Maguire, 1991).

Because education is the one domain where the use of many minority languages is actually increasing, schools themselves become, in effect, new speech communities, and very powerful ones too. Yet, in many cases such schools provide only a small minority of the population with access to linguistic resources which have become scarce in communicative practice in the public at large. The percentage of children attending the Diwan immersion schools in Breton or the Hawaiian immersion programs in Hawai'i is less than $5 \%$ of the population. Through such schooling, a small elite comes to possess a new variety of the traditional language equipped with modern terminology suitable for use in the new domains of use it has claimed.

The recent emergence of class varieties of many minority languages is a consequence of the struggle to reinstitutionalize and relegitimize minority languages in secondary agencies of social reproduction. The original defining group of speakers meanwhile becomes increasingly removed from control of their language as committees of experts coin new terms needed for specialized subject areas, and the language transmitted at school increasingly diverges from that spoken at home. Lack of secure home and community foundations for transmitting minority languages in many communities means that these new varieties, which are essentially 
class-based, may eventually replace traditional varieties. Until they do, their authenticity will be contested. At the same time, we cannot rule out the possibility that some of these speakers and varieties may provide a foundation for intergenerational transmission in the future.

Invoking the notion of 'hard' vs. 'soft' domain separation, Harris (1994: 148) argues that small indigenous communities should aim to have school as one of several safe culture and language havens. A safe haven is "a site of unambiguous culture expression such as an immersion school, a religious organization, or an adult language learning center." However, in the 'soft domain' version, where school is not complemented by use of the language at home, it has no chance of sustaining language revival and only a limited chance of enabling language maintenance. In this he appears to agree at least implicitly with Fishman. There are some other similarities between this view and Fishman's in so far as Harris (1994: 143) endorses "fairly strictly separated cultural domains" as essential for maintenance. The 'hard domain' version aims to position school as complementing strict domain separation between the home culture and family life on the one hand and the western world on the other.

However, even 'soft domain' schools have a reasonable chance of enabling competence to the point where the minority language is a language of identity. This is what I think we see happening in some of the situations described earlier. The Kahnawake Survival School dedicated to preserving Mohawk language culture and history represents one such example among many currently in existence among small indigenous language communities.

\section{CONCLUSION}

Fishman (2001: 461) himself warns of the danger of arriving at conclusions by overemphasizing a limited pool of historical experience. He observes that "most RLS theories and efforts are byproducts of European indigenous minority problems". Certainly, this reflects the fact that linguistic theory, like most scientific disciplines is grounded in western models rather than on indigenous epistemologies. He acknowledges the need for a general and more inclusive RLS theory. The ideological bias of his own model of RLS privileges intergenerational transmission, a fact which I think is not 
unconnected with the special status traditionally accorded within linguistic theory to native speakers. I would ask readers to take the criticisms I have offered here as part of what Fishman (1991: 394) himself has termed 'ideological clarification', i.e. a frank and open exploration of the goals of any RLS activity, as a prerequisite to planning. Indeed, in another context Fishman (1974: 84) is wary of the possibility of "universal and panchronic unidirectionality with respect to development and developmental planning." He advocates that developing nations must develop their own model of language planning and development compatible with their own sociolinguistic situations and their resources and goals.

Indigenous voices that have begun to make themselves heard in this arena are often angered at the suggestion that their language is dead, or that it is endangered and may die, and they resent such pronouncements and predictions from linguists, however wellintentioned (see Hill, 2002 for discussion of 'expert rhetorics' in advocacy for endangered languages). Jessie Little Doe Fermino, a Mashpee Wampanoag, whose language has not been spoken for centuries, articulates the belief that language is inalienable when she says (2001) "No matter what other language abides within us, we still carry the language of our creation within ourselves. To say that a part of our very being is dead is to say that we ourselves are dead." Similarly, Cherie Watkins, a Kaurna Aboriginal, whose language has not been used for well over a century, says "Some people have described Kaurna language as a dead language. But Kaurna people don't believe this. We believe that our language is a living language and that it has only been sleeping, and that the time to wake it up is now and this is what we are doing" (in Amery, 2001).

\section{ACKNOWLEDGEMENTS}

I am grateful to a number of scholars and audiences for constructive feedback, including Elana Shohamy, two anonymous referees, and participants at GURT 2006 (Georgetown University Roundtable on Linguistics) and at the Workshop on Language Ideologies and Change in Multilingual Communities at the University of California, San Diego. I would also like to thank Harold Schiffman for discussions concerning development of scientific terminology. 


\section{REFERENCES}

Abdulaziz, M. H. (1988). Development of scientific and technical terminology with special reference to African languages. Kiswahili, 56, 32-49.

Abley, M. (2003). Spoken here. Travels among threatened languages. Toronto: Random House of Canada.

Amery, R. (2001). Warrabarna Kaurna! Reclaiming an Australian language. Lisse: Swets \& Zeitlinger.

Ammon, U. (2001). English as a future language of teaching at German universities? A question of difficult consequences, posed by the decline of German as a language of science. In U. Ammon (Ed.), The dominance of English as a language of science. Effects on the non-English languages and language communities (pp. 343-361). Berlin/New York: Mouton de Gruyter.

Annamalai, E. (2005). Nation-building in a globalised world: Language choice and education in India. In Angel M. Y. Lin \& P. Martin (Eds), Decolonisation, globalization. Language-in-education policy and practice (pp. 20-38). Clevedon: Multilingual Matters.

Benton, R. (1999). Maori language revitalization. Wellington, NZ. Final report.

Black, P. (1990). Rethinking domain theory, part 1: how should it be applied? Ngoonjook, 3, 22-31.

Black, P. (1993). Rethinking domain theory, part 2: what about code-mixing? Ngoonjook, 8, 44-57.

Bourhis, R. Y. (2001). Reversing language shift in Quebec. In J. Fishman (Ed.), Can threatened languages be saved? Reversing language shift, revisited: A 21st century perspective (pp. 101-141). Clevedon: Multilingual Matters.

Brink, C. (2006). No lesser place. The taaldebat at Stellenbosch. Stellenbosch: Sun Press.

Brock-Utne, B. (2000). Whose education for all? The recolonization of the African mind. London: Falmer Press.

Brown R. M. 1998. A brief cultural history of the Guatemalan highlands. In: S. Garzon, R. M. Brown, J. B. Richards, \& Wuqu'Ajpub' (Arnulfo Simón) (Eds), The life of our language. Kaqchikel Maya maintenance, shift, and revitalization (pp. 44-61). Austin, TX: University of Texas Press.

Burridge, K. (2002). Steel tyres or rubber tyres - maintenance or loss: Pennsylvania German in the 'horse and buggy' communities of Ontario. In D. Bradley \& M. Bradley (Eds), Language endangerment and language maintenance (pp. 203-229). London: Routledge Curzon.

Calvet, L. J. (1993). La sociolinguistique. Paris: Presses Universitaires de France.

Canagarajah, A. S. (2005). Accommodating tensions in language-in-education policies: An afterword. In A. M. Y. Lin \& P. Martin (Eds), Decolonisation, globalisation. Language-in-education policy and practice (pp. 194-202). Clevedon: Multilingual Matters.

Criper, C. \& Dodd, W. (1984). Report on the teaching of English language and its use as a medium of education in Tanzania. Dar es Salaam: The British Council.

Crystal, D. (2000). Language death. Cambridge: Cambridge University Press.

Dalby, A. (2003). Language in danger. How language loss threatens our future. Harmondsworth: Penguin.

Dauenhauer, N. M. \& Dauenhauer, R. (1998). Technical, emotional, and ideological issues in reversing language shift: examples from Southeast Alaska. 
In L. A. Grenoble \& L. J. Whaley (Eds), Endangered languages. Current issues and future prospects (pp. 57-99). Cambridge: Cambridge University Press.

De Fréine, S. (1965). The great silence: the study of a relationship between language and nationality. Dublin: Mercier Press.

de Nebrija, A. [1492] (1926). Gramàtica de la lengua castellana. Oxford: Oxford University Press.

del Valle, J. (2000). Monoglossic policies for a heteroglossic culture: Misinterpreted multilingualism in modern Galicia. Language and Communication, 20(1), 105-132.

Dua, H. R. (1994). Hegemony of English. Mysore: Yashoda Publications.

Eckert, P. (1980). Diglossia: separate and unequal. Linguistics, 18, 1053-1064.

Eurydice (2005). Key data on teaching languages at school in Europe. Brussels: Eurydice European Unit.

Fabian, J. (1983). Time and the other. How anthropology makes its object. New York: Columbia University Press.

Fasold, R. (1984). The sociolinguistics of society. Oxford: Blackwell.

Ferguson, C. A. [1959] (1964). Diglossia. In: D. Hymes (Ed.), Language in culture and society: A reader in linguistics and anthropology (pp. 429-439). New York: Harper and Row (reprinted from Word 15:325-340).

Fermino, J. L. D. (2001). You are a dead people. Cultural Survival Quarterly, 25(2), 44-47. Summer Issue. Endangered Languages. Endangered Lives. edited by Eileen Quinn.

Fishman, J. A. (1967). Bilingualism with and without diglossia; diglossia with and without bilingualism. Journal of Social Issues, 23(2), 29-38.

Fishman, J. A. (1974). Language modernization and planning in comparison with other types of national modernization and planning. In Joshua A. Fishman (Ed.), Advances in language planning (pp. 79-102). The Hague: Mouton \& Co.

Fishman, J. A. (1991). Reversing language shift. Theoretical and empirical foundations of assistance to threatened languages. Clevedon: Multilingual Matters.

Fishman, J. A. (1997). Maintaining languages. What works and what doesn't. In G. Cantoni (Ed.), Stabilizing indigenous languages (pp. 186-198). Flagstaff, AZ: Northern Arizona University.

Fishman J. A. (2001). Can threatened languages be saved? Reversing language shift, revisited: A 21st Century perspective. Clevedon: Multilingual Matters.

Fishman, J. A. \& Markman, B. R. (1979). The ethnic mother tongue school in America: Assumptions, findings, directory. New York: Yeshiva University.

Giliomee, H., \& Schlemmer, L. (2001). Kruispad: Die toekoms van Afrikaans as openbare taal. [Crossroads: The future of Afrikaans as public language] Stellenbosch: Tafelberg.

Gill, S. K. (2004). Medium of instruction policy in higher education in Malaysia: Nationalism versus internationalization. In J. W. Tollefson \& A. B. M. Tsui (Eds), Medium of instruction policies - which agenda? whose agenda? (pp. 135-152). Mahwah, NJ: Lawrence Erlbaum.

Gilpin, A., Garrett, R. M., Kapinga, D. \& Kanyelele, M. (1996). Tanzania English language support project (ELTSP). Final report. London: Overseas Development Administration.

Gordon, R. G. Jr. (Ed.) (2005). Ethnologue: Languages of the World (15th ed.). Dallas: SIL International. Online version: http://www.ethnologue.com/, accessed May 28, 2006. 
Harris, S. (1994). 'Soft' and "hard' domain theory for bicultural education in indigenous groups. Peabody Journal of Education, 69(2), 140-153.

Hill, J. H. (2002). "Expert rhetorics" in advocacy for endangered languages: Who is listening, and what do they hear? Journal of Linguistic Anthropology, 12(2), 119-133.

Hornberger, N. \& King, K. (1999). Authenticity and unification in Quechua language planning. In S. May (Ed.), Indigenous Community-based Education (pp. 160-180). Clevedon: Multilingual Matters.

Hornsby, M. (2005). Néo-breton and questions of authenticity. Estudios de Sociolingüística, 6(2), 191-218.

Hudson, A. (2002). Outline of a theory of diglossia. International Journal of the Sociology of Language, 157, 1-48.

Jaffe, A. (1999). Ideologies in action. Language politics on Corsica. Berlin: Walter de Gruyter.

Jones, M. (1998). Language obsolescence and revitalization: Linguistic change in two Sociolinguistically contrasting Welsh communities. Oxford: Oxford University Press.

King, K. A. (2001). Language revitalization processes and prospects: Quichua in the Ecuadorian Andes. Clevedon: Multilingual Matters.

Krauss, M. (1992). The world's languages in crisis. Language, 68, 4-10.

Littlebear, R. (1999). Some rare and radical ideas for keeping indigenous languages. In: J. Reyhner, G. Cantoni, St. Clair, N. Robert, E. P. Yazzie (Eds), Revitalizing indigenous languages (pp. 1-5). Flagstaff, AZ: Northern Arizona University Press.

Maguire, G. (1991). Our own language: An Irish initiative. Clevedon: Multilingual Matters.

Malik, K. (2000). Let them die. Prospect, 57(November), 16-17.

Martel, A. (2001). When does knowledge have a national language? Language policy- making for science and technology. In U. Ammon (Ed.), The dominance of English as a language of science. Effects on the non-English languages and language communities (pp. 27-57). Berlin/New York: Mouton de Gruyter.

Martin-Jones, M. (1989). Language, power and linguistic minorities: the need for an alternative approach to bilingualism, language maintenance and shift. In: Grillo, Ralph (Ed.), Social anthropology and the politics of language (pp. 106-125). London: Routledge.

McConvell, P. (1992). Review of Fishman, J. A. 1991. Reversing language shift: Theoretical and empirical foundations of assistance to threatened languages. Australian Journal of Linguistics, 12(1), 209-220.

Mühlhäusler, P. (2002). Why one cannot preserve languages (but can preserve language ecologies). In D. Bradley \& M. Bradley (Eds), Language endangerment and language maintenance (pp. 34-39). London: Routledge Curzon.

Nettle, D. \& Romaine, S. (2000). Vanishing voices. The extinction of the world's languages. Oxford: Oxford University Press.

O'Rahilly, T. F. (1932). Irish dialects past and present: With chapters on Scottish and Manx. Dublin: Dublin Institute for Advanced Studies.

Ó Riagáin P. (1997). Language policy and social reproduction. Ireland 1893-1993. Oxford: Oxford University Press.

Ó Riagáin, P. (2001). Irish language production and reproduction 1981-1996. In: J. A. Fishman (Ed.), Can threatened languages be saved? Reversing language shift, 
revisited: A 21st century perspective (pp. 195-215). Clevedon: Multilingual Matters.

Pedraza, P. Jr., Attinasi, J. \& Hoffman, G. (1980). Rethinking diglossia. In: R. V. Padilla (Ed.), Ethnoperspectives in bilingual education research: Theory in bilingual education (pp. 76-97). Ypsilanti, MI: Department of Foreign Languages and Bilingual Studies. Eastern Michigan University.

Rajabu, R. \& Ngonyani, D. (1994). Language policy in Tanzania and the hidden agenda. In C. Rubagumya (Ed.), Teaching and researching language in African classrooms (pp. 6-15). Clevedon: Multilingual Matters.

Robins R. H. \& Uhlenbeck E. M. (1991). Endangered languages. Oxford: Berg.

Romaine, S. (1999). Women, land and language: Shifting metaphors and shifting languages. In: S. Wertheim, A. C. Bailey, \& M. Corston-Oliver (Eds), Engendering communication (pp. 473-486). Proceedings of the Fifth Berkeley Women and Language Conference. Berkeley Women and Language Group. Berkeley, California.

Romaine, S. (2002a). Can stable diglossia help to preserve endangered languages? International Journal of the Sociology of Language, 157, 135-140.

Romaine, S. (2002b). Signs of identity, signs of discord: Glottal goofs and the green grocer's glottal in debates on Hawaiian orthography. Journal of Linguistic Anthropology, 12(2), 189-225.

Romaine, S. forthcoming. Linguistic diversity, sustainability, and the future of the past. In: K. King, N. Schilling-Estes, L. Fogle, J. Lou, \& B. Soukup (Eds), Endangered and minority languages and varieties; Defining, documenting and developing. Washington, DC: Georgetown University Press.

Schiffman, H. F. forthcoming. Language policy and language conflict in Afghanistan and its neighbors. An introduction and overview.

Stille, A. (2002). The future of the past. How the information age threatens to destroy our cultural heritage. New York: Farrar, Straus and Giroux.

Shohamy, E. forthcoming. At what cost? Methods of reviving, maintaining and sustaining endangered and minority languages. In K. King, N. Schilling-Estes, L. Fogle, J. Lou, \& B. Soukup (Eds), Endangered and minority languages and varieties; Defining, documenting and developing. Washington, DC: Georgetown University Press.

Spolsky, B. (2003). Reassessing Māori regeneration. Language in Society, 32, $553-578$.

Spolsky, B. \& Shohamy, E. (2001). Hebrew after a century of RLS efforts. In J. A. Fishman (Ed.), Can threatened languages be saved? Reversing language shift, revisited: A 21st century perspective (pp. 350-364). Clevedon: Multilingual Matters.

Villanueva, M., Bishop, M. \& Meyer, K. N. forthcoming. American Sign Language: Endangered and endangering? In K. King, N. Schilling-Estes, L. Fogle, J. Lou, \& B. Soukup (Eds), Endangered and minority languages and varieties; Defining, documenting and developing. Washington, DC: Georgetown University Press.

Williams, G. (1992). Sociolinguistics. A sociological critique. London: Routledge.

Williams, G. \& Morris, D. (2000). Language planning and language use. Welsh in a global age. Cardiff: University of Wales Press.

Woolard, K. A. (1998). Introduction: Language ideology as a field of inquiry. In B. Schieffelin, K. A. Woolard \& P. V. Kroskrity (Eds), Language ideologies: Practice and theory (pp. 3-47). New York: Oxford University Press. 


\section{ABOUT THE AUTHOR}

Suzanne Romaine has been Merton Professor of English Language at the University of Oxford since 1984 and is the co-author of Vanishing Voices. The Extinction of the World's Languages. Address for correspondence: Merton College, University of Oxford, Oxford, OX1 4JD, UK. E-mail: suzanne.romaine@linguistics-philology. oxford.ac.uk 